\title{
Crystal structure of a TAPBPR-MHC-I complex reveals the mechanism of peptide editing in antigen presentation
}

\author{
Jiansheng Jiang, ${ }^{1 *}$ Kannan Natarajan, ${ }^{1 *}$ Lisa F. Boyd, ${ }^{1}$ Giora I. Morozov, ${ }^{1,2}$ Michael G. Mage, ${ }^{1}$ \\ David H. Margulies ${ }^{1} \uparrow$ \\ ${ }^{1}$ Molecular Biology Section, Laboratory of Immunology, National Institute of Allergy and Infectious Diseases, National Institutes of Health, Bethesda, MD 20892 , USA. \\ ${ }^{2}$ Hebrew University of Jerusalem, Robert H. Smith Faculty of Agriculture, Food and Environment, Rehovot, Israel 76100. \\ *These authors contributed equally to this work. \\ †Corresponding author. Email: dhm@nih.gov
}

Central to $\mathrm{CD}^{+} \mathrm{T}$-cell mediated immunity is the recognition of peptide-major histocompatibility complex class I (pMHC-I) proteins displayed by antigen-presenting cells. Chaperone-mediated loading of highaffinity peptides onto MHC-I is a key step in the MHC-I antigen presentation pathway. However, the structure of MHC-I with a chaperone that facilitates peptide loading has not been determined. We report the crystal structure of MHC-I in complex with the peptide editor TAPBPR (TAP binding protein, related), a tapasin homolog. TAPBPR remodels the peptide-binding groove of MHC-I, resulting in the release of lowaffinity peptide. Changes include groove relaxation, modifications of key binding pockets, and domain adjustments. This structure captures a peptide-receptive state of $\mathrm{MHC}-\mathrm{I}$ and provides insights into the mechanism of peptide editing by TAPBPR and, by analogy, tapasin.

Cell surface peptide-major histocompatibility complex class I (pMHC-I) complexes play a crucial role in adaptive and innate immunity by functioning as ligands for immunosurveillance by $\mathrm{CD} 8^{+} \mathrm{T}$ cells and natural killer cells $(1,2)$. Key to the intracellular assembly of pMHC-I complexes is the selective loading of high-affinity peptides, a process termed peptide editing. A dynamic series of steps involving peptide binding and exchange is orchestrated in the endoplasmic reticulum (ER) by tapasin or the closely related TAPBPR (3) to ensure that peptides of optimal affinity and length are assembled with MHC-I for display on the cell surface. Although the X-ray structure of tapasin in complex with the peptide-loading complex component ERp57 has been determined (4), structural data addressing the mechanism of peptide editing has been limited, likely due to the difficulty in generating crystallizable peptide-free (PF) or peptide-receptive (PR) MHC-I.

TAPBPR interacts directly with PF or PR MHC-I molecules, such as HLA-A*02:01 (HLA-A2) and H2- $\mathrm{D}^{\mathrm{d}}\left(\mathrm{D}^{\mathrm{d}}\right)$, generated by photolysis of co-assembled photosensitive peptides $(5,6)$. Attempts to crystallize purified TAPBPR-MHC-I complexes generated in this manner (fig. S1) were unsuccessful. Thus, we developed an alternative strategy to prepare partially peptide-filled yet stable pMHC-I molecules. Previous studies of MHC-I interactions with the related molecule, tapasin (7-11), as well as molecular dynamics (MD) simulations (12-17) suggest that the flexibility of the MHC-I F pocket, which accommodates the C-terminal amino acid of the peptide (18), is modulated by tapasin. Thus, we reasoned that pMHC-I molecules assembled with peptides truncated from the $\mathrm{C}$ terminus, leaving the $\mathrm{F}$ pocket unoccupied, would serve as effective ligands for TAPBPR. However, C-terminal truncated peptides failed to efficiently refold many MHC-I molecules, so we adapted an approach developed for the HLA-DM-HLA-DR1 complex $(19,20)$ and examined both human and mouse pMHC-I structures to identify those that would be amenable to disulfide linkage at central peptide positions (see materials and methods). Exploiting the stabilizing effect of a Gly-Leu dipeptide (see materials and methods), we successfully generated $\mathrm{D}^{\mathrm{d}} 73 \mathrm{C}$ molecules disulfide-linked to each of three peptides (table S1): full-length pI10C5 (RGPGCAFVTI) and two truncated versions (pA6C5 (RGPGCA) and pR5C5 (RGPGC)).

We next examined the binding of peptide- $\mathrm{D}^{\mathrm{d}} 73 \mathrm{C}$ complexes to human TAPBPR by surface plasmon resonance (SPR) (Fig. 1). $\mathrm{D}^{\mathrm{d}} 73 \mathrm{C}-10 \mathrm{mer}$ bound to TAPBPR with an equilibrium constant, $K_{\mathrm{D}}$, of $0.19 \mu \mathrm{M}$ and a dissociation rate constant, $k_{\mathrm{d}}$, of $0.024 \mathrm{~s}^{-1}$ (Fig. 1A). By contrast, the $\mathrm{D}^{\mathrm{d}} 73 \mathrm{C}-6 \mathrm{mer}$ (Fig. 1B) or $\mathrm{D}^{\mathrm{d}} 73 \mathrm{C}-5 \mathrm{mer}$ (Fig. 1C) bound with approximately ten-fold greater affinity $\left(K_{\mathrm{D}}\right.$ of $0.0094 \mu \mathrm{M}$ and $0.0091 \mu \mathrm{M}$ respectively) due primarily to smaller $k_{\mathrm{d}}$ values of $0.0013 \mathrm{~s}^{-1}$ and $0.0011 \mathrm{~s}^{-1}$, respectively. Statistical evaluation of the binding parameters is shown in Fig. 1, D and E. As shown previously for TAPBPR-MHC-I complexes prepared with HLA-A2, H2$\mathrm{D}^{\mathrm{b}}, \mathrm{H} 2-\mathrm{L}^{\mathrm{d}}$, as well as $\mathrm{H} 2-\mathrm{D}^{\mathrm{d}}(6)$, high-affinity peptide led to the dissociation of TAPBPR from $\mathrm{D}^{\mathrm{d}} 73 \mathrm{C}-5 \mathrm{mer}$ (fig. S2). The rate of dissociation by peptide was related to the affinity of the peptide for the MHC-I molecule (fig. S2) (5). 
We crystallized the chromatographically purified TAPBPR-D ${ }^{\mathrm{d}} 73 \mathrm{C}-5$ mer complex, merged the four best X-ray data sets, and solved a structure consisting of the TAPBPR lumenal domains, $\mathrm{D}^{\mathrm{d}} 73 \mathrm{C}$, and $\mathrm{h} \mathrm{\beta}_{2} \mathrm{~m}$. Crystals were of the $\mathrm{P} 3_{1}$ space group with four complexes in the asymmetric unit (table S2). The refined structure, at 3.4- $\AA$ resolution, had an $R_{\text {work }} / R_{\text {free }}(\%)$ of $24.2 / 26.9$, and satisfied standard validation criteria for proteins solved at this resolution. We focus our discussion on the first of four complexes in the asymmetric unit and note differences where relevant. In addition, crystal structures of unliganded $\mathrm{D}^{\mathrm{d}} 73 \mathrm{C}-10 \mathrm{mer}, \mathrm{D}^{\mathrm{d}} 73 \mathrm{C}-6 \mathrm{mer}$, and $\mathrm{D}^{\mathrm{d}} 73 \mathrm{C}-5$ mer were determined as summarized in table $\mathrm{S} 2$ and fig. S3.

The overall structure (Fig. 2) of the TAPBPR-D ${ }^{\mathrm{d}} 73 \mathrm{C}-5 \mathrm{mer}$ complex revealed a heterotrimer of TAPBPR-D ${ }^{\mathrm{d}} 73 \mathrm{C}$ heavy chain- $\beta_{2} \mathrm{~m}$ consistent with previous analytical ultracentrifugation and SPR data $(6)$. The $\mathrm{D}^{\mathrm{d}} 73 \mathrm{C}-\beta_{2} \mathrm{~m}$ heterodimer was nestled in a glove-like basket consisting of the $\mathrm{N}$ - and IgV-like domains of TAPBPR that clasp the $\alpha 2-1$ helix of $\mathrm{D}^{\mathrm{d}} 73 \mathrm{C}$ and extend a loop (residues 210 to 213, connecting strands $\beta_{13}$ and $\beta_{14}$ (fig. S4)) beneath the peptide-binding platform. This loop interacted with $\beta_{2} \mathrm{~m}$ and supported $\mathrm{D}^{\mathrm{d}} 73 \mathrm{C} \beta$-strands $6-8$ on the floor of the binding groove (Fig. 2, A to C). The composite TAPBPR N/IgV domain, which extends from the $\mathrm{N}$ terminus to residue 281 , consisted of $19 \beta$-strands with one short $3_{10^{-}}$ helix at residues 254-256. These $\beta$-strands were structurally similar to those of tapasin in the tapasin/ERp57 complex and reflect the sequence conservation among different TAPBPR species (fig. S4). The C-terminal domain (residues 282-377) revealed a typical IgC structure that notably forms part of an Ig-domain trimer coordinating with the Ig-like $\beta_{2} \mathrm{~m}$ and $\mathrm{D}^{\mathrm{d}} 73 \mathrm{C} \alpha 3$ domains (Fig. 2D). The TAPBPR-D ${ }^{\mathrm{d}} 73 \mathrm{C}$ interface (Fig. 2, E and F) buried an area of $1,884 \AA^{2}$ with $1,310 \AA^{2}$ contributed by $\mathrm{D}^{\mathrm{d}} 73 \mathrm{C}$ and $574 \AA^{2}$ by $\beta_{2} \mathrm{~m}$. The interface was dominated by 17 hydrogen bonds between TAPBPR and the $\mathrm{D}^{\mathrm{d}} 73 \mathrm{C}$ heavy chain, three salt bridges, with a total of 22 TAPBPR residue contacts (see table $\mathrm{S} 3$ ). Interactions with $\beta_{2} \mathrm{~m}$ were less extensive, with five hydrogen bonds and a total of nine TAPBPR residue contacts. This TAPBPR- ${ }^{\mathrm{d}} 73 \mathrm{C}$ structure was consistent with extensive mutagenesis data reported previously (21) (tables S4 and S5).

A comparison of the free and TAPBPR-bound forms of $\mathrm{D}^{\mathrm{d}} 73 \mathrm{C}-5 \mathrm{mer}$ revealed a distortion of the platform domain in the TAPBPR-complexed state (Fig. 3, A and B). In the region of direct contact between $\mathrm{D}^{\mathrm{d}} 73 \mathrm{C}-5$ mer and TAPBPR, the $\alpha 2$ 1-helix was pulled away by as much as $3 \AA$ (by interaction between residues 138 to 150 , particularly R144, R145, and $\mathrm{E} 148$ of $\mathrm{D}^{\mathrm{d}} 73 \mathrm{C}$, and residues of the palm of the glove of the TAPBPR N/IgV domain (Fig. 3, A and C, and table S3)). In addition, $\beta$-strand 8 of $\mathrm{D}^{\mathrm{d}} 73 \mathrm{C}$ was drawn down approximately $1.8 \AA$ (Fig. 3B and movie S1), and $\beta$-strand 5 was pulled by an interdigitating loop at the heel of the TAPBPR glove by as much as 1.4 $\AA$ (Fig. 3D). Other intermolecular interactions are listed in table S3. Interaction with TAPBPR distorted the peptide-binding groove. Notably, the side chain of Y84, which canonically coordinates both the $\mathrm{C}$ terminus of bound peptide and K146 of $\alpha 2-1$, flipped away from the groove to interact with E102 of TAPBPR (Fig. 3, E and F). The changes in this region deformed the $\mathrm{F}$ pocket, which normally accommodates the side chain of the C-terminal amino acid of the bound peptide. TAPBPR not only distorted the localized region of contact, but also exerted distal effects on the organization of $\mathrm{A}$ and $\mathrm{B}$ pocket residues that coordinate the $\mathrm{N}$ terminus of the bound peptide. In two of the four molecules in the asymmetric unit, the $\mathrm{D}^{\mathrm{d}} 73 \mathrm{C}$ R66 side chain extended across the binding groove to hydrogen-bond with Y159 effectively closing off this section (Fig. 3, G and H). As a consequence of these dynamic structural changes in the binding groove, electron density for the covalently bound 5 mer peptide and the GL dipeptide (used in refolding), and the accompanying peptide-stabilizing hydrogen-bonding network, clearly seen in the unliganded $\mathrm{D}^{\mathrm{d}} 73 \mathrm{C}-5 \mathrm{mer}$ (fig. S3, C, F, and $\mathrm{G}$ ), was no longer visualized in the TAPBPR complex. This lack of electron density of the covalently bound peptide, taken together with the widening of the groove at the $\mathrm{F}$ pocket region and rearrangements of key peptide-binding residues of $\mathrm{D}^{\mathrm{d}} 73 \mathrm{C}$, is consistent with the view that the covalently bound 5mer is mobile in the complex and is no longer tethered to the binding groove.

A comparison of the free and TAPBPR-bound forms of $\mathrm{D}^{\mathrm{d}} 73 \mathrm{C}-5 \mathrm{mer}$ also revealed dramatic movements of the MHCI $\alpha 3$ and $\beta_{2}$ m domains, which shifted $6.4 \AA$ and $4.4 \AA$, respectively, to engage TAPBPR (fig. S5 and movie S2). The repositioning of the $\mathrm{D}^{\mathrm{d}} 73 \mathrm{C} \alpha 3$ and $\beta_{2} \mathrm{~m}$ domains in the TAPBPR complex illustrates the coordinated and dynamic structural changes that occur when $\mathrm{D}^{\mathrm{d}} 73 \mathrm{C}$ interchanges between $\mathrm{PR}$ and peptide-loaded conformations.

An unanticipated result was the identification of important contacts of TAPBPR with $\beta_{2} \mathrm{~m}$. In the complex, several regions of TAPBPR $-\beta_{2} \mathrm{~m}$ contact were noted, including residues of the $\beta 1$ strand at the $\mathrm{N}$ terminus of $\beta_{2} \mathrm{~m}$, the loop at 59-60, which abuts loop 211-212 of TAPBPR, and C-terminal residues 92-94 of strand $\beta 7$ that bind residues 330 to 332 of the IgC domain of TAPBPR (Fig. 4, A to C). The significance of the $\beta_{2} \mathrm{~m}$ 58-60 loop is evidenced by reduced TAPBPR binding to $\mathrm{D}^{\mathrm{d}} 73 \mathrm{C}-5 \mathrm{mer}$ assembled with a $\beta_{2} \mathrm{~m}$ D59A mutant (Fig. 4 , E and G to I). Ala substitutions of $\beta_{2} \mathrm{~m}$ residues $\mathrm{I}$, or I92/K94 do not affect TAPBPR binding as severely as D59A (Fig. 4, D and $\mathrm{F}$ to I). Functional and binding studies have suggested the mutual contribution of $\beta_{2} \mathrm{~m}$ and bound peptide to MHC-I stability (22-25). Additionally, nuclear magnetic resonance studies of MHC-I reveal peptide-influenced changes in chemical shifts of the $\beta_{2} \mathrm{~m}$ 58-60 loop which abuts the floor of the peptide-binding platform (26).Thus, $\beta_{2} \mathrm{~m}$ 58- 
60 loop interactions with TAPBPR may not only stabilize PR MHC-I but also communicate the occupancy of the peptide binding groove-whether empty, partially occupied, or occupied by a low- or high-affinity peptide.

The crystal structure of the TAPBPR-Dd73C-5mer complex provides an X-ray structure of TAPBPR and permits direct comparison with the related tapasin. As implied by previous low-resolution SAXS structures (6) and anticipated by mutational and molecular dynamics studies (21,27), TAPBPR and tapasin, despite only $22 \%$ protein sequence identity, reveal remarkable structural similarity (see Fig. 2G). Mutational analyses $(4,6,8,9,21,28,29)$ and molecular dynamics simulations $(12,15,17)$, mapped the general region of the tapasin-MHC-I interaction to the MHC-I $\alpha 2$-1-helix and the $\alpha 3$ domain, sites that overlap with the TAPBPR-binding site (21). Notably, residues that interact with MHC-I are broadly conserved between TAPBPR and tapasin (fig. S4). Finally, the TAPBPR-D ${ }^{\mathrm{d}} 73 \mathrm{C}$ complex structure provides a basis for building a homology model of tapasin-HLA-B*44:02 (fig. S6) to guide further tests of the mechanism underlying the catalytic role of tapasin.

A comparison of the role of TAPBPR with that of HLADM, which similarly stabilizes a peptide-receptive conformation of the MHC-II molecule, revealed that these two classes of chaperone function by destabilizing diametrically opposite regions of the binding groove-TAPBPR affecting the F pocket (C-terminal portion) of the MHC-I groove directly, and HLA-DM distorting the $\mathrm{P} 1$ pocket ( $\mathrm{N}$-terminal portion) of the MHC-II. Although large structural changes in HLA-DR on HLA-DM binding in the P9 region have not been observed, a clear-cut effect of P9-substituted peptides on the stability of HLA-DM-HLA-DR complexes has been noted (19).

TAPBPR and tapasin function as both chaperone and peptide editor. As viewed through the X-ray structure of a peptide-dissociable TAPBPR-D ${ }^{\mathrm{d}} 73 \mathrm{C}-5 \mathrm{mer}$ complex described here, in which the 5mer represents a low affinity peptide, chaperone and editor functions are the result of the same structural effects: stabilization of an MHC-I conformation showing global differences in the $\alpha 2-1$ helix, the accessibility of the full peptide binding groove, including the $\mathrm{A}$ and $\mathrm{F}$ pockets, and the relative disposition of the $\alpha 3$ and $\beta_{2} \mathrm{~m}$ domains. We propose a model of TAPBPR-mediated peptide editing in which TAPBPR catalyzes dissociation of low affinity peptides, stabilizes PR (empty) MHC-I, and is released by high affinity peptide (Fig. 4J). By analogy, tapasin follows the same general structural principles.

This structural description of the interaction between MHC-I and TAPBPR provides insights into the molecular mechanism of peptide editing, an evolutionarily conserved and critical step in generating stable cell surface pMHC-I complexes for immunological surveillance. Additionally, this work provides a basis for further structural and computational approaches modeling additional components of the TAPBPR- and tapasin-mediated peptide presentation pathways.

\section{REFERENCES AND NOTES}

1. J. S. Blum, P. A. Wearsch, P. Cresswell, Pathways of antigen processing. Annu. Rev. Immunol. 31, 443-473 (2013). doi:10.1146/annurev-immunol-032712-095910 Medline

2. K. L. Rock, E. Reits, J. Neefjes, Present yourself! By MHC class I and MHC class II Molecules. Trends Immunol. 37, 724-737 (2016). doi:10.1016/j,it.2016.08.010 Medline

3. L. H. Boyle, C. Hermann, J. M. Boname, K. M. Porter, P. A. Patel, M. L. Burr, L. M. Duncan, M. E. Harbour, D. A. Rhodes, K. Skjødt, P. J. Lehner, J. Trowsdale, Tapasin-related protein TAPBPR is an additional component of the MHC class I presentation pathway. Proc. Natl. Acad. Sci. U.S.A. 110, 3465-3470 (2013). doi:10.1073/pnas.1222342110 Medline

4. G. Dong, P. A. Wearsch, D. R. Peaper, P. Cresswell, K. M. Reinisch, Insights into MHC class I peptide loading from the structure of the tapasin-ERp57 thiol oxidoreductase heterodimer. Immunity 30, 21-32 (2009). doi:10.1016/.immuni.2008.10.018 Medline

5. C. Hermann, A. van Hateren, N. Trautwein, A. Neerincx, P. J. Duriez, S. Stevanović, J. Trowsdale, J. E. Deane, T. Elliott, L. H. Boyle, TAPBPR alters MHC class I peptide presentation by functioning as a peptide exchange catalyst. eLife 4, e09617 (2015). doi:10.7554/eLife.09617 Medline

6. G. I. Morozov, H. Zhao, M. G. Mage, L. F. Boyd, J. Jiang, M. A. Dolan, R. Venna, M. A. Norcross, C. P. McMurtrey, W. Hildebrand, P. Schuck, K. Natarajan, D. H. Margulies, Interaction of TAPBPR, a tapasin homolog, with MHC-I molecules promotes peptide editing. Proc. Natl. Acad. Sci. U.S.A. 113, E1006-E1015 (2016). doi:10.1073/pnas.1519894113 Medline

7. M. Chen, M. Bouvier, Analysis of interactions in a tapasin/class I complex provides a mechanism for peptide selection. EMBO J. 26, 1681-1690 (2007). doi:10.1038/sj.emboj.7601624 Medline

8. A. L. Peace-Brewer, L. G. Tussey, M. Matsui, G. Li, D. G. Quinn, J. A. Frelinger, A point mutation in HLA- $A^{*} 0201$ results in failure to bind the TAP complex and to present virus-derived peptides to CTL. Immunity 4, 505-514 (1996). doi:10.1016/S10747613(00)80416-1 Medline

9. A. P. Williams, C. A. Peh, A. W. Purcell, J. McCluskey, T. Elliott, Optimization of the MHC class I peptide cargo is dependent on tapasin. Immunity 16, 509-520 (2002). doi:10.1016/S1074-7613(02)00304-7 Medline

10. H. R. Turnquist, S. E. Vargas, E. L. Schenk, M. M. Mcllhaney, A. J. Reber, J. C. Solheim, The interface between tapasin and MHC class I: Identification of amino acid residues in both proteins that influence their interaction. Immunol. Res. 25 , 261-269 (2002). doi:10.1385/IR:25:3:261 Medline

11. H. R. Turnquist, S. E. Vargas, A. J. Reber, M. M. Mcllhaney, S. Li, P. Wang, S. D. Sanderson, B. Gubler, P. van Endert, J. C. Solheim, A region of tapasin that affects $\mathrm{L}^{\mathrm{d}}$ binding and assembly. J. Immunol. 167, 4443-4449 (2001). doi:10.4049/jimmunol.167.8.4443 Medline

12. E. T. Abualrous, S. Fritzsche, Z. Hein, M. S. Al-Balushi, P. Reinink, L. H. Boyle, U. Wellbrock, A. N. Antoniou, S. Springer, F pocket flexibility influences the tapasin dependence of two differentially disease-associated MHC Class I proteins. Eur. J. Immunol. 45, 1248-1257 (2015). doi:10.1002/eji.201445307 Medline

13. F. Sieker, T. P. Straatsma, S. Springer, M. Zacharias, Differential tapasin dependence of MHC class I molecules correlates with conformational changes upon peptide dissociation: A molecular dynamics simulation study. Mol. Immunol. 45, 3714-3722 (2008). doi:10.1016/j.molimm.2008.06.009 Medline

14. F. Sieker, S. Springer, M. Zacharias, Comparative molecular dynamics analysis of tapasin-dependent and -independent MHC class I alleles. Protein Sci. 16, 299-308 (2007). doi:10.1110/ps.062568407 Medline

15. K. Ostermeir, S. Springer, M. Zacharias, Coupling between side chain interactions and binding pocket flexibility in HLA-B*44:02 molecules investigated by molecular dynamics simulations. Mol. Immunol. 63, 312-319 (2015). do::10.1016/j.molimm.2014.07.021 Medline

16. M. A. Garstka, S. Fritzsche, I. Lenart, Z. Hein, G. Jankevicius, L. H. Boyle, T. Elliott, J. Trowsdale, A. N. Antoniou, M. Zacharias, S. Springer, Tapasin dependence of 
major histocompatibility complex class I molecules correlates with their conformational flexibility. FASEB J. 25, 3989-3998 (2011). doi:10.1096/fj.11190249 Medline

17. O. Fisette, S. Wingbermühle, R. Tampé, L. V. Schäfer, Molecular mechanism of peptide editing in the tapasin-MHC I complex. Sci. Rep. 6, 19085 (2016). doi:10.1038/srep19085 Medline

18. M. A. Saper, P. J. Bjorkman, D. C. Wiley, Refined structure of the human histocompatibility antigen HLA-A2 at 2.6 A resolution. J. Mol. Biol. 219, 277-319 (1991). doi:10.1016/0022-2836(91)90567-P Medline

19. A. K. Anders, M. J. Call, M.-S. E. D. Schulze, K. D. Fowler, D. A. Schubert, N. P. Seth, E. J. Sundberg, K. W. Wucherpfennig, HLA-DM captures partially empty HLA-DR molecules for catalyzed removal of peptide. Nat. Immunol. 12, 54-61 (2011). doi:10.1038/ni.1967 Medline

20. W. Pos, D. K. Sethi, M. J. Call, M.-S. E. D. Schulze, A.-K. Anders, J. Pyrdol, K. W. Wucherpfennig, Crystal structure of the HLA-DM-HLA-DR1 complex defines mechanisms for rapid peptide selection. Cell 151, 1557-1568 (2012). doi:10.1016/i.cell.2012.11.025 Medline

21. C. Hermann, L. M. Strittmatter, J. E. Deane, L. H. Boyle, The binding of TAPBPR and tapasin to MHC class I is mutually exclusive. J. Immunol. 191, 5743-5750 (2013). doi:10.4049/jimmunol.1300929 Medline

22. S. Kozlowski, T. Takeshita, W.-H. Boehncke, H. Takahashi, L. F. Boyd, R. N. Germain, J. A. Berzofsky, D. H. Margulies, Excess beta 2 microglobulin promoting functional peptide association with purified soluble class I MHC molecules. Nature 349, 74-77 (1991). doi:10.1038/349074a0 Medline

23. J. R. Cook, N. B. Myers, T. H. Hansen, Peptide ligand structure influences the exchange of $\beta_{2}$-microglobulin by cell surface $\mathrm{K}^{\mathrm{b}}$. Mol. Immunol. 35, 929-934 (1998). doi:10.1016/S0161-5890(98)00080-7 Medline

24. R. A. Smith, N. B. Myers, M. Robinson, T. H. Hansen, D. R. Lee, Polymorphism at position 97 in MHC class I molecules affects peptide specificity, cell surface stability, and affinity for $\beta_{2}$-microglobulin. J. Immunol. 169, 3105-3111 (2002). doi:10.4049/jimmunol.169.6.3105 Medline

25. M. J. Shields, W. Hodgson, R. K. Ribaudo, Differential association of beta2microglobulin mutants with MHC class I heavy chains and structural analysis demonstrate allele-specific interactions. Mol. Immunol. 36, 561-573 (1999). doi:10.1016/S0161-5890(99)00077-2 Medline

26. M. Beerbaum, M. Ballaschk, N. Erdmann, C. Schnick, A. Diehl, B. Uchanska-Ziegler, A. Ziegler, P. Schmieder, NMR spectroscopy reveals unexpected structural variation at the protein-protein interface in MHC class I molecules. J. Biomol. NMR 57, 167-178 (2013). doi:10.1007/s10858-013-9777-z Medline

27. C. Thomas, R. Tampé, Proofreading of peptide-MHC complexes through dynamic multivalent interactions. Front. Immunol. 8, 65 (2017). doi:10.3389/fimmu.2017.00065 Medline

28. L. C. Simone, X. Wang, A. Tuli, J. C. Solheim, Effect of a tapasin mutant on the assembly of the mouse MHC class I molecule H2- $\mathrm{K}^{\mathrm{d}}$. Immune Cell Biol. 88, 57-62 (2010). Medline

29. Y. Y. Yu, H. R. Turnquist, N. B. Myers, G. K. Balendiran, T. H. Hansen, J. C. Solheim, An extensive region of an MHC class I $\alpha 2$ domain loop influences interaction with the assembly complex. J. Immunol. 163, 4427-4433 (1999). Medline

30. A. Neerincx, C. Hermann, R. Antrobus, A. van Hateren, H. Cao, N. Trautwein, S. Stevanović, T. Elliott, J. E. Deane, L. H. Boyle, TAPBPR bridges UDPglucose:glycoprotein glucosyltransferase 1 onto MHC class I to provide quality control in the antigen presentation pathway. eLife 6, e23049 (2017). doi:10.7554/eLife.23049 Medline

31. A. A. Dombkowski, Disulfide by design: A computational method for the rational design of disulfide bonds in proteins. Bioinformatics 19, 1852-1853 (2003). doi:10.1093/bioinformatics/btg231 Medline

32. H. Li, K. Natarajan, E. L. Malchiodi, D. H. Margulies, R. A. Mariuzza, Threedimensional structure of $\mathrm{H}-2 \mathrm{D}^{\mathrm{d}}$ complexed with an immunodominant peptide from human immunodeficiency virus envelope glycoprotein 120. J. Mol. Biol. 283, 179-191 (1998). doi:10.1006/imbi.1998.2091 Medline

33. S. K. Saini, K. Ostermeir, V. R. Ramnarayan, H. Schuster, M. Zacharias, S. Springer, Dipeptides promote folding and peptide binding of MHC class I molecules. Proc. Natl. Acad. Sci. U.S.A. 110, 15383-15388 (2013). doi:10.1073/pnas.1308672110 Medline

34. W. Kabsch, XDS. Acta Crystallogr. D 66, 125-132 (2010).
doi:10.1107/S0907444909047337 Medline

35. K. Diederichs, M. Junk, Post-processing intensity measurements at favourable dose values. J. Appl. Crystallogr. 42, 48-57 (2009). doi:10.1107/S0021889808036716

36. A. J. McCoy, R. W. Grosse-Kunstleve, P. D. Adams, M. D. Winn, L. C. Storoni, R. J. Read, Phaser crystallographic software. J. Appl. Crystallogr. 40, 658-674 (2007). doi:10.1107/S0021889807021206 Medline

37. P. D. Adams, P. V. Afonine, G. Bunkóczi, V. B. Chen, I. W. Davis, N. Echols, J. J. Headd, L.-W. Hung, G. J. Kapral, R. W. Grosse-Kunstleve, A. J. McCoy, N. W. Moriarty, R. Oeffner, R. J. Read, D. C. Richardson, J. S. Richardson, T. C. Terwilliger, P. H. Zwart, PHENIX: A comprehensive Python-based system for macromolecular structure solution. Acta Crystallogr. D 66, 213-221 (2010). doi:10.1107/S0907444909052925 Medline

38. P. Emsley, B. Lohkamp, W. G. Scott, K. Cowtan, Features and development of Coot. Acta Crystallogr. D 66, 486-501 (2010). doi:10.1107/S0907444910007493 Medline

39. G. F. Schröder, M. Levitt, A. T. Brünger, Super-resolution biomolecular crystallography with low-resolution data. Nature 464, 1218-1222 (2010). doi:10.1038/nature08892 Medline

40. E. F. Pettersen, T. D. Goddard, C. C. Huang, G. S. Couch, D. M. Greenblatt, E. C. Meng, T. E. Ferrin, UCSF Chimera-A visualization system for exploratory research and analysis. J. Comput. Chem. 25, 1605-1612 (2004). doi:10.1002/jcc.20084 Medline

41. E. Krissinel, K. Henrick, Inference of macromolecular assemblies from crystalline state. J. Mol. Biol. 372, 774-797 (2007). doi:10.1016/i.jmb.2007.05.022 Medline

42. M. Corr, L. F. Boyd, E. A. Padlan, D. H. Margulies, H-2Dd exploits a four residue peptide binding motif. J. Exp. Med. 178, $1877-1892$ (1993). doi:10.1084/jem.178.6.1877 Medline

\section{ACKNOWLEDGMENTS}

We thank P. Sun and P. Roche for discussions and comments on the manuscript, and J. Skinner for guidance on statistics. This research was supported by the Intramural Research Program of the National Institute of Allergy and Infectious Diseases, NIH. Data were collected at SER-CAT (22-ID) and GM/CA-CAT (23ID) beamlines at the Advanced Photon Source (APS), Argonne National Laboratory. Use of the APS was supported by the U.S. Department of Energy, Office of Science, Office of Basic Energy Sciences, under Contract No. W-31-109-Eng-38. GM/CA@APS has been funded in whole or in part with Federal funds from the National Cancer Institute (ACB-12002) and the National Institute of General Medical Sciences (AGM-12006). X-ray structure factors and refined coordinates have been deposited in the Protein Data Bank (www.wwpdb.org) under accession numbers: 5WER, 5WES, 5WET, and 5WEU for TAPBPR-Dd73C-5mer, D 73 C-5mer, Dd73C-6mer, and D 73 C-10mer, respectively. Author contributions: J.J., K.N., L.F.B., G.I.M., M.G.M., and D.H.M. planned experiments, generated constructs, expressed and purified protein, and performed and analyzed binding data. J.J. and K.N. performed crystallization screens. J.J. and K.N. collected and scaled diffraction data and solved the structures by molecular replacement, and performed crystallographic refinement. J.J. performed data merging, scaling, extensive refinement and model building. J.J., K.N., L.F.B., M.G.M. and D.H.M. wrote the paper. We dedicate this paper to the memory of our friend and colleague, William E. Paul.

\section{SUPPLEMENTARY MATERIALS}

www.sciencemag.org/cgi/content/full/science.aa05154/DC1

Materials and Methods

Figs. S1 to $\mathrm{S} 6$

Tables S1 to S5

References (31-42)

Movies S1 and S2

28 July 2017; accepted 4 October 2017

Published online 12 October 2017

10.1126/science.aao5154 

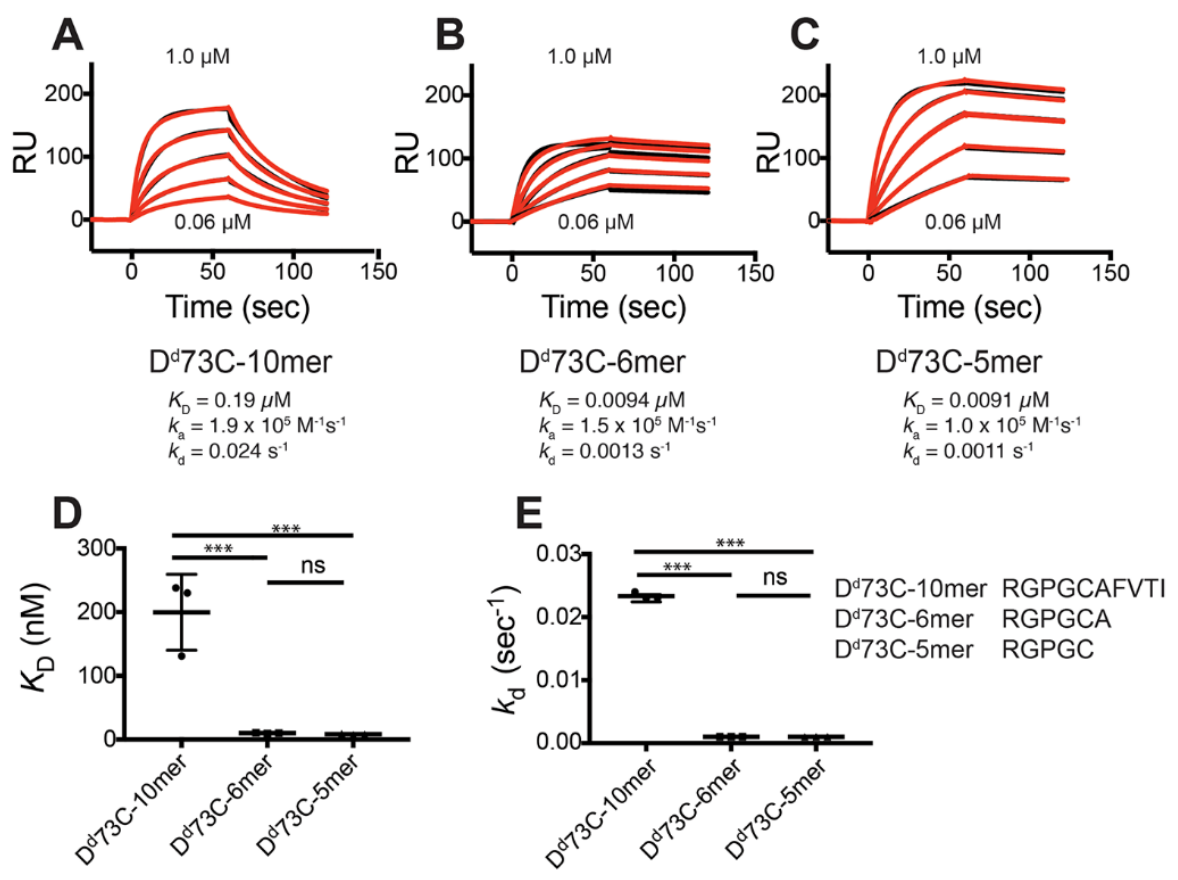

Fig. 1. Kinetics and affinity of the interaction between TAPBPR and $D^{d} 73 C$ containing disulfide-linked peptide. (A to E) SPR analysis of the interaction between TAPBPR and $\mathrm{D}^{\mathrm{d}} 73 \mathrm{C}-10 \mathrm{mer}(\mathrm{A}), \mathrm{D}^{\mathrm{d}} 73 \mathrm{C}-6 \mathrm{mer}$ $(B)$, and $D^{d} 73 C-5 m e r(C)$. Data are shown in red and fits of the data to a 1:1 binding model are overlaid in black. The results of three independent experiments $(M \pm S D)$ are shown as scatter plots in (D) and $(\mathrm{E}) .{ }^{* *}, \mathrm{p}<0.05$ (one-way ANOVA). 



Fig. 2. Overall structure of the TAPBPR-D $73 C-h \beta_{2} m-5 m e r$ complex. (A) Ribbon representation of TAPBPR (pink), $\mathrm{D}^{\mathrm{d}} 73 \mathrm{C}$ heavy chain (blue), and $\beta_{2} \mathrm{~m}$ (green), with individual domains of TAPBPR and structural elements of $D^{d} 73 C$ labeled. (B) Similar to (A) but with $D^{d} 73 C$ and $\beta_{2} m$ in surface representation. (C) Similar to (A) but with TAPBPR in surface representation. (D) Ribbon and surface representation of the Ig-domain trimer composed of the TAPBPR IgC domain, $\mathrm{D}^{\mathrm{d}} 73 \mathrm{C} \alpha 3$, and $\beta_{2} \mathrm{~m}$. (E) Surface representation of $D^{d} 73 C$ and $\beta_{2} m$ with interface residues highlighted in blue and green, respectively, $D^{d} 73 C-\beta_{2} m$ was rotated to the left by approximately $90^{\circ}$. (F) Surface representation of TAPBPR with interface residues highlighted in pink (rightward rotation of $90^{\circ}$ ). 


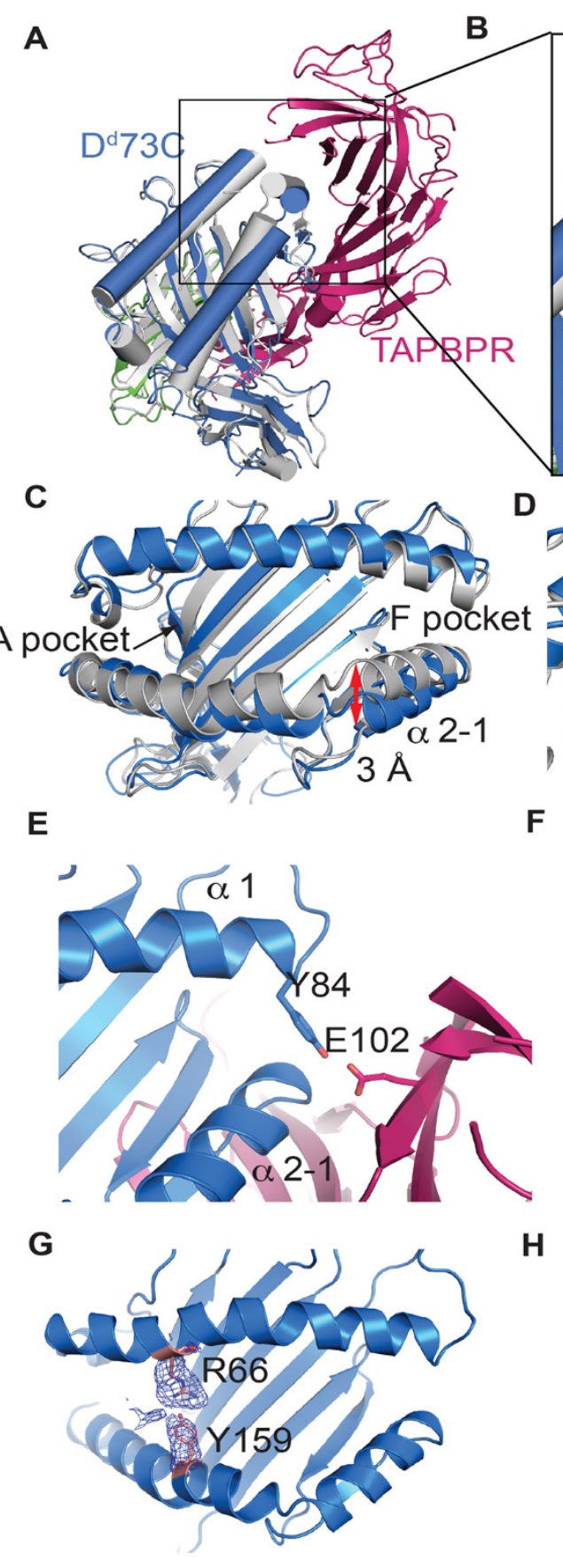

$D^{d} 73 C-5 m e r$ complexed with TAPBPR

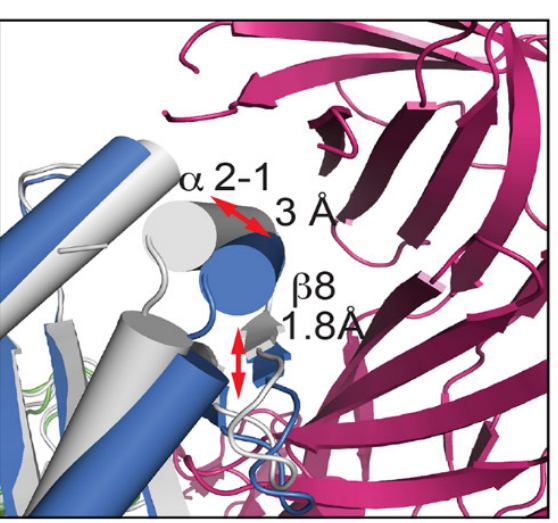

D

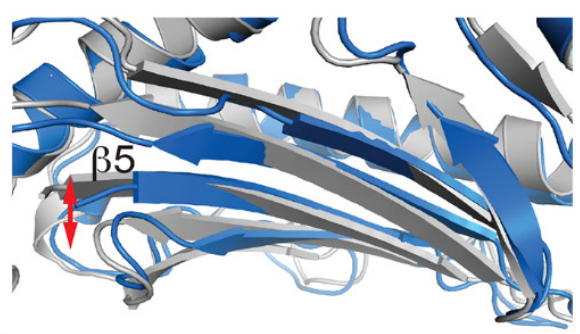

$\mathbf{F}$

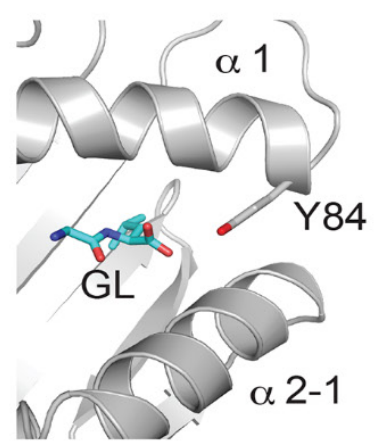

H

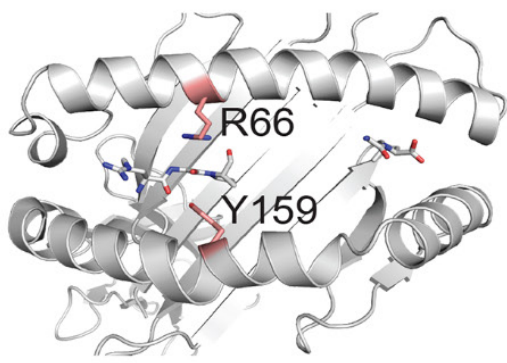

$D^{d} 73 C-5 m e r$ uncomplexed
Fig. 3. TAPBPR remodels $D^{d} 73 C$ binding groove. (A to $C$ ) Superposition of the platform domain of $\mathrm{D}^{\mathrm{d}} 73 \mathrm{C}$ in the unliganded (gray) and TAPBPR-bound (blue) forms. TAPBPR is pink. Groove widening $(B, C)$ at $\alpha 2-1$ helix is indicated by arrows. (D) Comparison of floor of the peptidebinding groove of $\mathrm{D}^{\mathrm{d}} 73 \mathrm{C}$ in the unliganded (gray) and TAPBPRbound (blue) forms. Movement of the $\beta$ strands is depicted by arrow. (E) Contact between $Y 84$ in the $\alpha 1$ helix of $D^{d} 73 C$ (blue) with E102 of TAPBPR (pink). (F) Y84 of Dd73C5 mer (gray) contacts GL dipeptide (cyan) in $F$ pocket in absence of TAPBPR. (G) Steric blocking of the $A / B$ pocket of $D^{d} 73 C$ in the TAPBPR-bound form by side-chain interactions between R66 and Y159. Electron density for these residues is depicted in dark blue. $(\mathbf{H})$ Disposition of R66 and $\mathrm{Y} 159$ in unliganded $\mathrm{D}^{\mathrm{d}} 73 \mathrm{C}-5 \mathrm{mer}$ when the groove is occupied by peptide. 
A
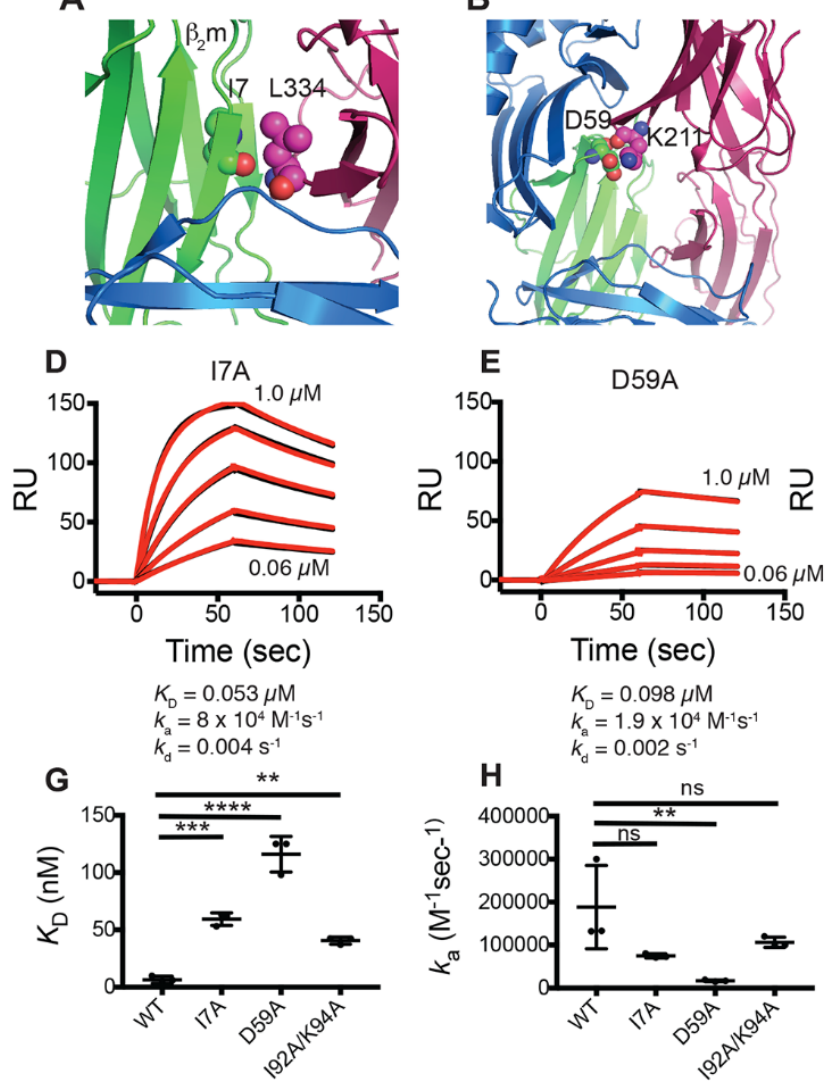

$K_{\mathrm{D}}=0.098 \mu \mathrm{M}$

$k_{\mathrm{a}}=1.9 \times 10^{4} \mathrm{M}^{-1} \mathrm{~s}^{-1}$
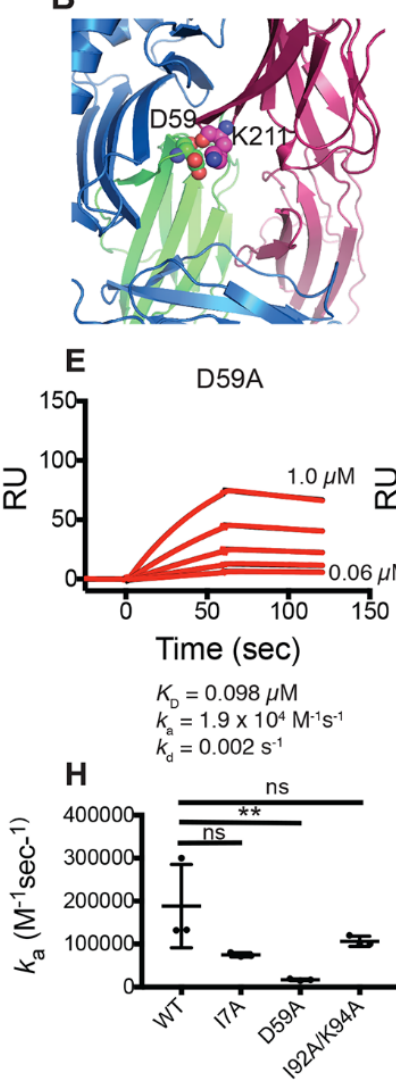

C

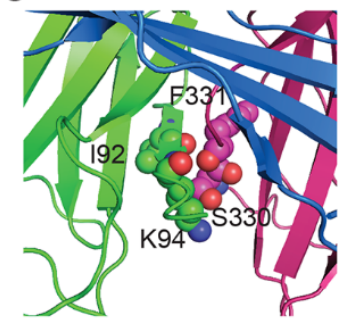

$\mathbf{F}$

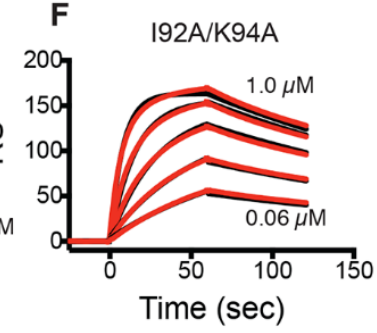

$K_{\mathrm{D}}=0.042 \mu \mathrm{M}$

$k_{\mathrm{a}}=9.9 \times 10^{4} \mathrm{M}^{-1} \mathrm{~s}^{-1}$

$k_{\mathrm{d}}=0.004 \mathrm{~s}^{-1}$

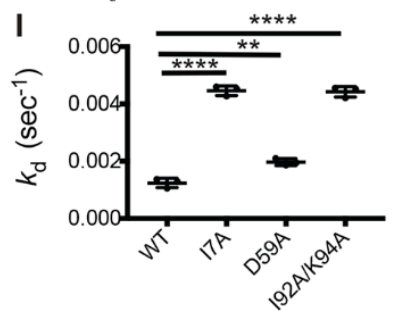

J

1 low affinity peptide

(LA)

2

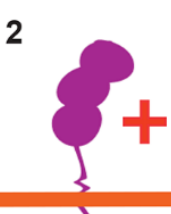

त 3

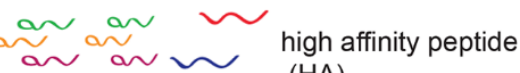

to cell surface

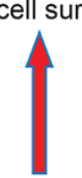

TAPBPR MHC-I-low affinity

peptide

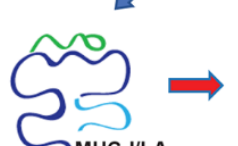

3

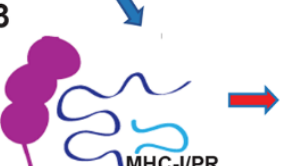

4

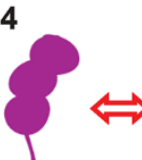

$\Leftrightarrow$

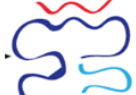

TAPBPR-MHC-I complex Binding of high affinity peptide Groove remodeling: $\alpha 2-1$ and $\beta 8$ drawn to TAPBPR.

$F$ pocket widened.

A pocket occluded.

$\alpha 3$ and $\beta 2 \mathrm{~m}$ reoriented.

No peptide in binding groove.
Fig. 4. Importance of $\beta_{2} \mathrm{~m}-$ TAPBPR contacts and mechanism of peptide editing as viewed through the structure of TAPBPR-MHC-I complex. (A to $C)$ close-up view of contact residues between $h \beta_{2} \mathrm{~m}$ and TAPBPR: (A) $\beta_{2} \mathrm{~m} 17$ to TAPBPR L334; (B) $\beta_{2} \mathrm{~m}$ D59 to TAPBPR K211; (C) $\quad \beta_{2} \mathrm{~m} \quad 192 / \mathrm{K} 94$ to TAPBPR S330/F331. (D to F) Summary of binding of $\mathrm{D}^{\mathrm{d}} 73 \mathrm{C}$ 5 mer complexes assembled with the indicated mutant $\mathrm{h} \beta_{2} \mathrm{~m}$ chains. ( $G$ to I) Summary of binding parameters as compared with WT $(M \pm S D)$. Asterisks indicate degree of statistical significance of means of multiple determinations: ****, $\mathrm{p}<0.001$; $*^{* *}, p \leq 0.006$; ${ }^{* *}, p<0.03$ (oneway ANOVA). (J) Model for TAPBPR function in peptide presentation: 1. Various peptides, ranging from low-affinity (LA) to high-affinity $(\mathrm{HA})$ are provided to the ER following cytoplasmic proteolysis and TAP-mediated transport; 2. TAPBPR binds to MHC-I bearing a low-affinity peptide (MHC-I/LA) or a peptide of suboptimal length, and catalyzes peptide dissociation; 3 . TAPBPR binding remodels the peptide groove causing release of the low-affinity peptide, and stabilization of PF MHC-I (TAPBPR=MHC-I_PR); 4. upon binding a high-affinity peptide, MHC-I-PR conformation changes to $\mathrm{MHC}-\mathrm{I}-\mathrm{HA}$ (high affinity), dissociates from TAPBPR (see fig. S2) and is transported to the cell surface. This model addresses only the effects of interactions of TAPBPR with MHC-I. Further experiments are needed to structurally clarify the recently described recycling pathway that employs UDPglucose:glycoprotein glucosyltransferase (UGT1) (30). 